\title{
Functionally Thrombasthenic State in Normal Platelets Following the Administration of Ticlopidine
}

Giovanni Di Minno, Anna M. Cerbone, Pier L. Mattioli, Salvatore Turco, Ciro lovine, and Mario Mancini

Istituto Di Medicina Interna e Malattie Dismetaboliche, Clinica Medica, Nuovo Policlinico, Napoli, Italy

\begin{abstract}
To elucidate the bleeding tendency that follows the administration of ticlopidine, we investigated the skin bleeding time and some ex vivo functions of platelets obtained from eight healthy volunteers before and 1 wk after daily administration of 500 mg of ticlopidine. We found the following: ticlopidine significantly $(P<0.001)$ prolonged the skin bleeding time and impaired the binding of radiolabeled fibrinogen and von Willebrand Factor, the clot retraction and the aggregation of platelets in response to ADP, epinephrine, thrombin, ionophore A23187, collagen, or arachidonic acid. In contrast, the administration of this drug did not affect intraplatelet levels of cAMP, agglutination and binding of von Willebrand Factor in response to ristocetin, shape change in response to $\mathrm{ADP}$, collagen, thrombin, or arachidonic acid, or binding of prostaglandin $\mathbf{E}_{1}$ to resting platelets. Secretion of ATP in response to ADP or epinephrine was completely inhibited, whereas secretion as well as thromboxane synthesis in response to high concentrations of collagen, arachidonic acid, calcium ionophore A23187, or thrombin was unaffected. Studies with monoclonal antibodies showed that the glycoprotein IIb-IIIa complex (the putative receptor for fibrinogen and von Willebrand Factor on the surface of platelets exposed to naturally occurring aggregating agents) was quantitatively unaffected by ticlopidine. This observation was further confirmed by densitometric scannings of Periodic Acid-Schiff-stained gels of platelet suspensions. The onset, as well as the cessation of the inhibitory effect of ticlopidine on platelets was very slow, and reached a maximum after a 3-5-d administration. In addition, ticlopidine appeared to be a much more potent inhibitor when administered to subjects than when added in vitro to platelets. Finally, abnormalities comparable to those found in volunteers taking ticlopidine were observed when platelets from untreated subjects were incubated in the plasma of ticlopidine-treated subjects.

We conclude that ticlopidine induces a thrombasthenic state in normal platelets without affecting the glycoprotein IIbIIIa complex quantitatively. Furthermore, our data suggest that one or more active metabolites rather than the native drug
\end{abstract}

Portions of this work were presented at a symposium ("Ticlopidine: Quo vadis?") in Montpellier, France, 1983, and were published in abstract form in the proceedings of that symposium.

Address reprint requests to Dr. Di Minno.

Received for publication 22 March 1984 and in revised form 11 September 1984.

J. Clin. Invest.

(c) The American Society for Clinical Investigation, Inc.

$0021-9738 / 85 / 02 / 0328 / 11 \quad \$ 1.00$

Volume 75, February 1985, 328-338 mediate the abnormalities of platelet function observed in ticlopidine-treated subjects.

\section{Introduction}

The key role of blood platelets in thrombogenesis and atherogenesis has fostered the search for new drugs interfering with platelet function more selectively and effectively than aspirin.

Ticlopidine (5-[2chlorobenzyl]-4,5,6,7,tetrahydrothieno[3,2C]pyridine hydrochloride) has been shown to inhibit ex vivo the aggregation of platelets in response to a variety of agents, to prevent the primary aggregation in response to ADP, to decrease the adhesion of platelets to glass surfaces, and to prolong the skin bleeding time (see reference 1 for a review). The interaction of fibrinogen with platelets plays a central role in platelet physiology (2-11), and recent data (12-16) have emphasized the role of ADP, thromboxane (Tx), ${ }^{1}$ and cAMP in the exposure of specific receptors for fibrinogen on the platelet surface. In this report we present evidence that ticlopidine almost suppresses the binding of fibrinogen to platelets without affecting the intraplatelet levels of cAMP, the formation of $\mathrm{TxB}_{2}$ and the secretion of nucleotides in response to high concentrations of collagen, arachidonic acid, ionophore A23187, or thrombin.

Abnormally prolonged bleeding time, defective adhesion of platelets to glass surfaces, defective ADP-induced first wave of aggregation and normal $\mathrm{TxB}_{2}$ synthesis, and secretion of nucleotides in response to high concentrations of collagen, ionophore A23187, or thrombin are known to occur in Glanzmann's thrombasthenia $(2,3,17-21)$. Platelets from these patients lack the glycoprotein IIb-IIIa (GPIIb-IIIa) complex (22, 23) and exhibit negligible binding of fibrinogen after stimulation with ADP (24-28) and deficient binding of von Willebrand Factor (vWF) when exposed to thrombin (29). Since GPIIb-IIIa may form complexes with fibrinogen (30), and monoclonal antibodies to GPIIb and/or IIIa may impair the binding of fibrinogen as well as of vWF to platelets (15, 31-34), such glycoproteins are currently thought to be the receptor for these adhesive proteins on the surface of platelets exposed to naturally occurring aggregating agents. To elucidate whether the impaired platelet aggregation, fibrinogen, and vWF binding observed after the administration of ticlopidine might be due to abnormalities of this receptor, we used two monoclonal antibodies specific to this complex. The data

1. Abbreviations used in this paper: AA, arachidonic acid; DTT, dithiothreitol; GPIIb-IIIa, glycoprotein IIb-IIla; PFP, platelet-free plasma; PRP, platelet-rich plasma; $\mathrm{PG}$, prostaglandin; $\mathrm{PGE}_{1}, \mathrm{PGE}_{2}, \mathrm{PGF}_{1 \alpha}$, and $\mathrm{PGF}_{2 \alpha}$, prostaglandins $\mathrm{E}_{1}, \mathrm{E}_{2}, \mathrm{~F}_{1 \alpha}$, and $\mathrm{F}_{2 \alpha} ; \mathrm{Tx}$, thromboxane; vWF, von Willebrand Factor. 
obtained indicate that ticlopidine may induce the functional abnormalities of thrombasthenia in platelets in the absence of GPIIb-IIIa deficiency.

\section{Methods}

Disodium EDTA, basic fuchsin, and dithiothreitol (DTT) were obtained from Fisher Scientific Co., King of Prussia, PA. EDTA was used as a 100 -mM stock solution in distilled water (pH adjusted to 7.4 with $\mathrm{NaOH}$ solution). SDS was from Pierce Chemical Co., Rockford, IL. Ammonium persulphate, acrylamide, $N$ - $N$-methylene-bis-acrylamide, and molecular weight standards were from Bio-Rad Laboratories, Richmond, CA. Bovine serum albumin (Pentex, fraction V) was from Miles Laboratories Inc., Elkhart, IN. Prostaglandin $\mathrm{E}_{1}\left(\mathrm{PGE}_{1}\right)$, hirudin, Hepes, ATP, and ADP (ADP and triphosphate sodium salts) were from Sigma Chemical Co., St. Louis, MO. PGE 1 was dissolved and stored as previously described (35); ADP, ATP, and hirudin were dissolved in distilled water and stored at $-20^{\circ} \mathrm{C}$ in small aliquots; Hepes was prepared as a stock solution of $1 \mathrm{M}$ and stored at $4^{\circ} \mathrm{C}$. Epinephrine (epinephrine hydrochloride, isotonic solution) was from Elkins-Sinn Inc., Cherry Hill, NJ. Arachidonic acid (AA) and calcium ionophore A23187 were kindly provided by Dr. Renato Saggiorato (Menarini Diagnostici, Florence, Italy) and prepared and stored as previously described (36). Thrombin was obtained from Parke Davis \& Co., Detroit, MI, dissolved in distilled water, and stored in small aliquots at $-70^{\circ} \mathrm{C}$. Equine tendon collagen was from Hormon Chemie, München, Federal Republic of Germany. Protosol, ${ }^{14} \mathrm{C}$-carboxylinulin, sodium iodide $\left({ }^{125} \mathrm{I}\right)$ and radiolabeled $\mathrm{PGE}_{1}\left(\mathrm{PGE}_{1}-5,6-{ }^{3} \mathrm{H}\right.$, specific activity $>60 \mathrm{Ci} / \mathrm{mmol}$ ) were from New England Nuclear, Florence, Italy. Istagel scintillation fluid and Tri-Carb 2660 beta-counter were from Packard Instruments Co. Inc. (Downers Grove, IL). Highly specific antibodies to $\mathrm{TxB}_{2}$ (Seragen Inc., Boston, MA) exhibited $<0.03 \%$ cross-reactivity with prostaglandins $\mathrm{E}_{2}, \mathrm{~F}_{2 \alpha}$, 6-keto-PGF $\mathrm{F}_{1 \alpha}$, and $\mathrm{D}_{2}$. Silicone oils (methyl silicone 1.0 DC 200 and Hi phenyl silicone 125 DC 550) were purchased from W. F. Nye, Inc., Specialty Lubricants, New Bedford, MA. Mixtures of DC 200 and DC 550 were prepared as described previously (15). Reptilase was from Pentapharm, Basel, Switzerland. Ticlopidine (powder and 250-mg tablets) and its parachlorobenzyl isomer PCR 5325 were kindly provided by Drs. Eric Vallee, Sanofi Recherche, Toulouse, France, and Luca Piovella, Clin Midy Milan, Italy. vWF, purified, characterized, and labeled as described by Ruggieri et al. (34) was a gift of Dr. A. Federici, Milan, Italy. Monoclonal antibodies B79.7 (IgG1) and B59.2 (IgG2a) were kindly provided by Dr. P. Thiagarajan, Thomas Jefferson University, Philadelphia, PA. B79.7 is similar to antibody B59.2, which has been previously shown to be specific for the GPIIb-IIIA complex (15). Indeed, like B59.2, antibody B79.7 (or its Fab fragments) inhibited aggregation and fibrinogen binding to platelet suspensions in a dosedependent fashion and bound only negligibly $(<5 \%)$ to platelets from three patients with Glanzmann's thrombasthenia. Moreover, like unlabeled B59.2, antibody B79.7 cross-competes $>98.7 \%$ with labeled antibody B59.2 for the binding to stimulated or unstimulated platelets. For binding studies, antibody B79.7 and B59.2 were labeled with ${ }^{125}$ I by the iodine monochloride method (37). For both aggregation and binding studies, mouse immunoglobulins were used as controls throughout.

Preparation of platelet suspensions. Blood was collected from eight healthy subjects (five males, three females, 26-32-yr-old) before and 1 wk after daily administration of $250 \mathrm{mg}$ of Ticlopidine b.i.d. From each subject, $9 \mathrm{vol}$ of blood $(90 \mathrm{ml})$ were collected $12-14 \mathrm{~h}$ after the last administration of Ticlopidine from the antecubital vein via a 19gauge scalp vein needle into a plastic tube containing 1 vol $(10 \mathrm{ml})$ $3.8 \%$ trisodium citrate. Platelet-rich plasma (PRP) obtained by centrifugation (200 $\mathrm{g}$ for $15 \mathrm{~min})$ at room temperature was used as such within $2 \mathrm{~h}$. Platelet-free plasma (PFP) was obtained by centrifuging fresh PRP in an Eppendorf centrifuge (Beckman Analytical, Milan, Italy) at $12,000 \mathrm{~g}$ for $5 \mathrm{~min}$. For preparation of platelet suspensions, aliquots of PRP were cooled on ice for $30 \mathrm{~min}$ and EDTA was added to a final concentration of $5.6 \mathrm{mM}$. After centrifugation at $2,000 \mathrm{~g}$ for 6 min at $4^{\circ} \mathrm{C}$ in a Beckmann $\mathrm{J}-6 \mathrm{~B}$ centrifuge, the platelets were resuspended, as previously described (15), in a volume of buffer $(0.14$ $\mathrm{M} \mathrm{NaCl}, 20 \mathrm{mM}$ Tris, $5 \mathrm{mM}$ glucose, and $1 \mathrm{mM}$ EDTA, pH 7.4) equal to that of the discarded plasma, centrifuged at $900 \mathrm{~g}$ for $6 \mathrm{~min}$ at room temperature and resuspended at counts in the range of 1-5 $\times 10^{8} / \mathrm{ml}$ in a Tyrode's buffer $(0.14 \mathrm{M} \mathrm{NaCl}, 2.7 \mathrm{mM} \mathrm{KCl}, 1 \mathrm{mM}$ $\mathrm{CaCl}_{2}, 12 \mathrm{mM} \mathrm{NaHCO}_{3}$, and $0.4 \mathrm{mM} \mathrm{NaH}_{2} \mathrm{PO}_{4}$ ) containing $5 \mathrm{mM}$ glucose, $3.5 \mathrm{mg} / \mathrm{ml}$ bovine serum albumin, and $10 \mathrm{mM}$ Hepes, $\mathrm{pH}$ 7.4. Platelet counts were determined by phase-contrast microscopy. When trace amount of ${ }^{125}$ I-fibrinogen or ${ }^{125} \mathrm{I}-\mathrm{vWF}$ were added to the PRP, $>99.9 \%$ of these proteins were removed by the washing procedure. Platelets washed and resuspended in this manner showed "swirling" as a gross indication of maintenance of discoid shape. Platelet suspensions contained $<0.5 \mu \mathrm{g} / \mathrm{ml}$ fibrinogen as measured by the staphylococcal clumping test (Boehringer Mannheim, Milan, Italy, sensitivity $<0.5$ $\mu \mathrm{g} / \mathrm{ml})(38)$ and did not aggregate in response to $100 \mu \mathrm{M}$ ADP or 1 $\mu \mathrm{g} / \mathrm{ml}$ collagen unless fibrinogen ( $200 \mathrm{nM}$ final) was added. Studies on aggregation of washed platelets were carried out in the presence of 200 $\mathrm{nM}$ fibrinogen. The aggregating response of washed platelets in the presence of fibrinogen was $80-90 \%$ of that seen in autologous PRP and was unchanged for at least $2 \mathrm{~h}$. All aggregation and binding studies were conducted within $2 \mathrm{~h}$. Rat blood, obtained by heart puncture from 15 female CD-COBS anesthetized with ether vapor, was collected into plastic tubes containing 1 vol of $3.8 \%$ trisodium citrate. PRP was obtained by centrifugation of the blood for $15 \mathrm{~min}$ at $220 \mathrm{~g}$ and employed as such for aggregation studies or processed as described above for human PRP for the preparation of platelet suspensions. Platelet aggregation and fibrinogen binding were determined as described below for platelets from humans.

Fibrinogen purification and labeling. Fibrinogen was purified from normal donor citrated plasma by the method of Martinez et al. (39). The purified fibrinogen contained $<0.8 \%$ immunoassayable fibronectin and vWF. Fibrinogen, labeled with ${ }^{125}$ I by the iodine monochloride method of McFarlane (37) had a specific activity of 2.6-3.8 $\times 10^{4}$ $\mathrm{cpm} / \mu \mathrm{g}$ protein. Unlabeled and labeled fibrinogen showed the characteristic $A_{\alpha}, B_{\beta}$, and $\gamma$ peaks, without any degradation products, when electrophoresed on reduced SDS-polyacrylamide gels (40). Further details of the properties of fibrinogen prepared and labeled in this manner have been previously reported (39).

Platelet aggregation and thromboxane formation. Platelet aggregation tests were performed in plastic cuvettes in the Elvi 840 aggregometer (Elvi-Logos, Milan, Italy). The apparatus was adjusted so that PRP (or suspensions of washed platelets) and PFP (or buffer) produced 10 and $90 \%$ light transmittance, respectively. When thrombin was the stimulus used, hirudin $(0.2-10 \mathrm{U} / \mathrm{ml})$ was employed to prevent clotting. $\mathrm{TxB}_{2}$ levels were measured by a radioimmunoassay (41) in aliquots of the supernatant solution of tests for platelet aggregation. The sensitivity was such that as little as $0.5 \mathrm{pmol} \mathrm{TxB}_{2} / 3 \times 10^{8}$ platelets could be detected.

Platelet secretion of ATP. Secretion of ATP was determined as described elsewhere (41) in a Lumi-aggregometer (Mascia Brunelli, Milan, Italy). This apparatus records the luminescence resulting from the interaction of released ATP (secreted simultaneously with ADP) with firefly luciferase and luciferin (Chronolume 395, Chrono-log Corp., Havertown, PA). The sensitivity was such that concentrations of released ATP as low as $0.1 \mu \mathrm{M}$ could be detected.

cAMP determination. cAMP was measured on samples of PRP and of platelet suspensions essentially as described by Remuzzi et al. (42) employing a commercially available kit for radioimmunoassay (Beckton-Dickinson, Novate Milanese, Italy). Briefly, $1 \mathrm{ml}$ of $5 \%$ TCA was added to $1 \mathrm{ml}$ of PFP or PRP that had been previously incubated for $1 \mathrm{~min}$ with microliter amounts of buffer or with concentrations of 
$\mathrm{PGE}_{1}(1 \mu \mathrm{M})$ that completely inhibited the aggregation of PRP from normals. The sample was immediately frozen in liquid nitrogen and thawed at room temperature, then shaken at $4^{\circ} \mathrm{C}$ for $30 \mathrm{~min}$. After centrifugation at $3,000 \mathrm{~g}$ for $30 \mathrm{~min}$ at $4^{\circ} \mathrm{C}$, the supernatant was extracted with water saturated ether and the residual ether evaporated under nitrogen. When trace amounts of ${ }^{3} \mathrm{H}$-cAMP were added to the PRP, $>90 \%$ of this nucleotide could be recovered at the end of the procedure. For each PRP the amount of cAMP present in the PFP was subtracted. CAMP of the PFP was always $<10 \mathrm{pmol} / \mathrm{ml}$. cAMP of rat platelets was determined in a similar fashion.

Platelet clot retraction. The platelet-fibrin clot retraction was measured on PRP as described elsewhere (43). Briefly, a series of samples, each containing $0.5 \mathrm{ml}$ of unstirred PRP, were incubated at $37^{\circ} \mathrm{C}$ with 1-10 $\mu \mathrm{l}$ of each retracting agent or vehicle. After $3 \mathrm{~min}, 0.1 \mathrm{ml}$ Reptilase was added and the mixture was stirred with a small glass rod then left inside the tube. At time intervals between 10 and $60 \mathrm{~min}$ after the addition of Reptilase, the rod, to which the clot was attached, was gently removed from duplicate samples and the serum was measured in a microliter syringe. The amount of clot retraction was calculated by relating the volume of serum to the total amount of initial mixture and expressed as a percentage. When thrombin was the retracting agent used, Reptilase was omitted.

Studies on fibrinogen, antibody and $v W F$ binding to platelets. Binding of ${ }^{125} \mathrm{I}$-fibrinogen (or of ${ }^{125} \mathrm{I}-\mathrm{B} 79.7$ ) to platelet suspensions was performed as reported previously (15) with some modifications. Briefly, the time dependence of binding was studied by incubating at room temperature $\left(22^{\circ} \mathrm{C}\right) 6 \mathrm{ml}$ of unstirred platelet suspension $\left(3-5 \times 10^{8} /\right.$ $\mathrm{ml}$ ) with $10 \mu \mathrm{M} \mathrm{AA}, 0.5 \mu \mathrm{g} / \mathrm{ml}$ collagen, $10 \mu \mathrm{M}$ epinephrine, $10 \mu \mathrm{M}$

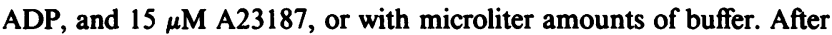
a 3-min incubation, labelled fibrinogen (or B79.7) was added at the final concentration of $100 \mu \mathrm{g} / \mathrm{ml}$. At intervals (30 s-120 min), $0.4 \mathrm{ml}$ of the platelet suspension was removed and layered onto $50 \mu \mathrm{l}$ of silicone oil in a $0.5 \mathrm{ml}$ micro-Eppendorf tube, and free and plateletbound ligand were separated by centrifugation for $2 \mathrm{~min}$ at $12,000 \mathrm{~g}$ in an Eppendorf centrifuge and counted in a Beckman DP 5,500 gammacounter. The effect of increasing concentrations of ADP, collagen, AA, A23187, or epinephrine on the extent of fibrinogen binding to platelets was assessed by incubating unstirred platelet suspensions with ADP (5-30 $\mu \mathrm{M})$, collagen $(0.5-3 \mu \mathrm{g} / \mathrm{ml})$, AA (5-30 $\mu \mathrm{M})$, thrombin (5-30 mU/ml), ionophore A23187 (5-30 $\mu \mathrm{M})$, or epinephrine (5-30 $\mu \mathrm{M})$. After $3 \mathrm{~min}$, labeled fibrinogen ( $200 \mathrm{nM}$, final concentration) was added and the extent of binding was determined 5 min later. For dose-response studies, 500- $\mu$ l aliquots of unstirred platelets were incubated with each aggregating agent (or with equal amounts of buffer) for $3 \mathrm{~min}$, after which labeled fibrinogen (or B79.7) was added in final concentrations of 1.5-2,400 nM. Fibrinogen binding was measured 5 min later while B79.7 binding was measured after $1 \mathrm{~min}$. Specific fibrinogen binding was calculated by subtracting from the total bound the binding measured in the presence of a 20 -fold excess of unlabeled protein. This latter "nonspecific" binding represented $<20 \%$ of the total bound. Specific fibrinogen binding was not (51) corrected for the amount of this protein bound in the absence of stimulation, which was <4-5\% of stimulated binding. Studies on the inhibition of aggregation and fibrinogen binding to platelets by antibody B79.7 were carried out as previously described for antibody B59.2 (15). Binding of ${ }^{125} \mathrm{I}-\mathrm{vWF}$ to thrombin-, collagen-, AA-, ionophore A23187-, and ADP-stimulated platelets was performed as previously reported (44), while binding of ${ }^{125} \mathrm{I}-\mathrm{vWF}$ to ristocetin-stimulated platelets was carried out as described by Kao et al. (45).

Whole platelet glycoprotein analysis. Reduced samples for whole platelet glycoprotein analysis were prepared by mixing $500 \mu$ l platelet suspension (containing $\sim 1-2 \times 10^{9}$ platelets) with an equal volume of a 6\% SDS solution and $250 \mu \mathrm{l}$ of a $0.2 \mathrm{M}$ solution of DTT. The samples were then heated at $100^{\circ} \mathrm{C}$ for $3 \mathrm{~min}$ and centrifuged at $12,000 \mathrm{~g}$ for $10 \mathrm{~min}$ in an Eppendorf centrifuge. Polyacrylamide gels, $1.5 \mathrm{~mm}$ thick, contained a bis-acrylamide ratio of $0.67 \%$ with a $7.5 \%$ (wt/vol) acrylamide. Aliquots ( $\sim 300 \mu \mathrm{g}$ protein) of the supernatant were loaded on the gels and run in a discontinuous SDS-Tris-glycine system employing a vertical slab gel electrophoresis cell (Bio-Rad Laboratories). Gels were run at $40 \mathrm{~mA}$ constant current until the front (visible as refractive index difference) reached the bottom of the gel. Running time was $\sim 4-5 \mathrm{~h}$. Gels, fixed and stained with Schiff's reagents according to Clementson et al. (46), were soaked twice in $7.5 \%$ acetic acid and scanned at $550 \mathrm{~nm}$ in a spectrodensitometer model SD 3,000 connected with a SDC 300 density computer (Schoeffel Instruments Corp., Westwood, NJ).

Binding of $P G E_{1}$ to resting platelets. Binding of radiolabeled $\mathrm{PGE}_{1}$ to resting platelets was carried out essentially as described by McDonald and Stuart (47) with some modifications. Briefly, appropriate amounts of ${ }^{3} \mathrm{H}-\mathrm{PGE}_{1}$ were added to a solution of unlabeled ligand to yield a 5$\mu \mathrm{M}$ solution of specific activity $0.5 \mathrm{Ci} / \mathrm{mmol}$. Binding procedures were performed at $37^{\circ} \mathrm{C}$. The time dependence was determined by incubating $3 \mathrm{ml}$ of unstirred PRP (obtained from four normal subjects before and 1 wk after daily administration of $500 \mathrm{mg}$ of ticlopidine) with $32 \mathrm{nM}$

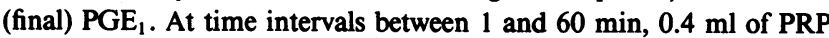
were removed and free and platelet-bound $P_{1} E_{1}$ separated in silicone oil. After centrifugation, the supernatant plasma and silicone oil were carefully aspirated with a Pasteur pipette, and a cotton tip applicator was used to remove residual plasma from the walls of the conical tubes and the top of the platelet pellet. The tips of the tubes and known amounts of the supernatants were placed in scintillation vials containing $1 \mathrm{ml}$ of Protosol and allowed to stand overnight to dissolve the pellet. A 10-ml vol of scintillation fluid was then added and the vials counted for radioactivity. For dose-response studies, $500-\mu 1$ aliquots of PRP were incubated with increasing concentrations (from 16 to $512 \mathrm{nM}$, final) of $P E_{1}$ and binding determined $5 \mathrm{~min}$ later. In some experiments, the quantity of radioactivity trapped with the pelleted platelets was measured by adding trace amounts of ${ }^{14} \mathrm{C}$-inulin to PRP 5 min before centrifugation and determining the amount of ${ }^{14} \mathrm{C}$-inulin present in the platelet pellet. Trapping never exceeded $0.5 \%$ of the total bound, and this value was subtracted from the total binding. Specific binding was also corrected for the amount of this prostaglandin bound in the presence of a 20-fold excess of unlabeled $P E_{1}$ that was $23-26 \%$ of the total bound.

Bleeding time. The skin bleeding time was determined with a Simplete II apparatus (General Diagnostic, Warner Lambert Co., Morris Plains, NJ) according to the manufacturer's recommendations.

Protein concentration. Protein concentration was calculated from the absorbance at $280 \mathrm{~nm}$ using an extinction coefficient of 15.1 for fibrinogen and 14.3 for antibodies.

Statistical analysis. $t$ Test for paired comparison was used for statistical analysis.

Informed consent. Informed consent was obtained from all the volunteers in accordance with accepted institutional practices. The studies were carried out according to the principles of the declaration of Helsinki.

\section{Results}

Prolongation of the bleeding time after the administration of ticlopidine. After 1 wk of ticlopidine administration there was a significant prolongation of the skin bleeding time in all the subjects studied $(4.96 \pm 1.1$ min before vs. $9.16 \pm 1.12$ after, $P$ $<0.001$ ). One volunteer had nose bleeding, and five out of eight exhibited easy bruising. No further prolongation of the bleeding time was observed in four volunteers to whom ticlopidine ( $500 \mathrm{mg}$ daily) was administered for $1 \mathrm{mo}$.

Effect of ticlopidine on platelet aggregation, ATP secretion, $T \times B_{2}$ synthesis, and intraplatelet cAMP. In vitro addition of ticlopidine (100 $\mu \mathrm{M}$, final) to PRP or to washed platelet 
suspensions did not change the sensitivity of these cells to aggregating agents. In contrast, after 1 wk of administration, the aggregation of PRP in response to ADP (5-15 $\mu \mathrm{M})$, epinephrine (5-15 $\mu \mathrm{M})$, collagen $(0.125-0.75 \mu \mathrm{g} / \mathrm{ml})$, thrombin $(0.1-0.5 \mathrm{U} / \mathrm{ml})$, or AA $(0.2-0.6 \mathrm{mM})$, was almost suppressed (Fig. 1). Similar impairment of platelet aggregation was observed when the calcium ionophore A23187 (5-15 $\mu \mathrm{M})$ was the stimulus employed (not shown). The administration of ticlopidine did not affect agglutination of PRP and of formaldehydefixed platelets in response to ristocetin and shape change in response to ionophore $\mathrm{A} 23187$ (not shown) or to ADP, collagen, thrombin, and AA (Fig. 1). Likewise, the intraplatelet levels of cAMP, determined before and after exposure to $\mathrm{PGE}_{1}$ (1 $\mu \mathrm{M}$ ), were unaffected by ticlopidine (Table I). When the secretion of ATP was measured simultaneously with the aggregation, it appeared that ticlopidine suppressed secretion in response to ADP or epinephrine, whereas it only partially affected secretion in response to AA, ionophore A23187, collagen, or thrombin. This partial inhibition of secretion was further evaluated. Dose-response studies revealed (Fig. 2) that the inhibition of secretion by ticlopidine could only be detected when low concentrations of AA, collagen, or thrombin were used. Furthermore, normal secretion of ATP (i.e., 3.7 \pm 0.72 $\mu \mathrm{M})$ was also observed when unstirred platelet suspensions from ticlopidine-treated subjects were preincubated in vitro with $5 \mathrm{mM}$ EDTA (in order to avoid aggregation) and 25-50 $\mu \mathrm{M}$ of ionophore A23187 were added 5 min later. In parallel

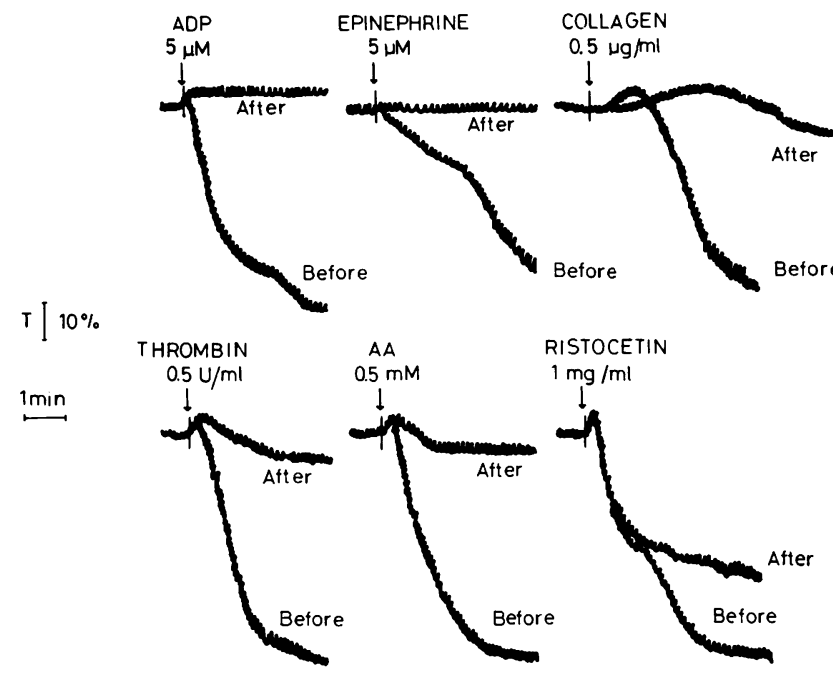

Figure 1. Effect of the administration of ticlopidine on platelet aggregation. Microliter amounts of each aggregating agent were incubated with $0.25 \mathrm{ml}$ of PRP which had been stirred at $37^{\circ} \mathrm{C}$ for $1 \mathrm{~min}$ at $1,000 \mathrm{rpm}$. The apparatus was calibrated so that PRP and PFP produced 10 and $90 \%$ light transmittance, respectively. The extent of platelet aggregation was determined 3 min after the addition of each aggregating agent. The inhibitory effect of ticlopidine on the aggregation induced by all the agents (but ristocetin) and the lack of inhibition of the shape change in response to ADP, collagen, AA, or thrombin are evident in this figure. The seven other PRPs studied gave similar results. Similar inhibitory effects of ticlopidine were also observed on suspensions of washed platelets $\left(5 \times 10^{8} / \mathrm{ml}\right)$ stirred in the presence of fibrinogen ( $200 \mathrm{nM}$ final) for $1 \mathrm{~min}$ before adding each aggregating agent. No shape change was seen before or after ticlopidine when epinephrine was the stimulus employed.
Table I. Changes of cAMP Content in Platelets Obtained Before and After the Administration of Ticlopidine*

\begin{tabular}{lcc}
\hline & \multicolumn{2}{c}{$\operatorname{cAMP}\left(\right.$ pmol$/ 10^{9}$ platelets) } \\
\cline { 2 - 3 } Stimulus & Before & After \\
\hline Buffer & $67.8 \pm 14.1$ & $72.2 \pm 16.3$ \\
PGE $_{1}(1 \mu \mathrm{M})$ & $188.9 \pm 21.2 \ddagger$ & $201.3 \pm 29.1 \ddagger$ \\
\hline
\end{tabular}

A $1-\mathrm{ml}$ solution of $5 \%$ TCA was added to $1 \mathrm{ml}$ of PRP or PFP previously incubated for $1 \mathrm{~min}$ with buffer or with a concentration of PGE $_{1}(1 \mu \mathrm{M})$ that completely suppressed the aggregation of platelets. The sample was immediately frozen in liquid nitrogen and thawed at room temperature, then shaken at $4^{\circ} \mathrm{C}$ for $30 \mathrm{~min}$. After centrifugation at $3,000 \mathrm{~g}$ for $30 \mathrm{~min}$ at $4^{\circ} \mathrm{C}$, the supernatant was extracted with water-saturated ether and cAMP measured by a radioimmunoassay. For each PRP the amount of cAMP present in the PFP was subtracted.

* Mean \pm SEM of composite data from all eight subjects.

$\ddagger P<0.001$ buffer vs. $P G E_{1}$-treated platelets $(P>0.05$ for all the other comparisons).

with secretion, $\mathrm{TxB}_{2}$ synthesis was only affected in response to low concentrations of these agents (Fig. 3).

Results similar to those seen employing PRP were found when aggregation, ATP secretion, $\mathrm{TxB}_{2}$ synthesis, and intraplatelet CAMP were determined in washed platelet suspensions from normal subjects and in PRP or washed platelet suspensions from rats treated with ticlopidine (data not shown).

Inhibition of clot retraction by ticlopidine. In parallel with the inhibition of platelet aggregation, ticlopidine almost suppressed the retraction of PRP clotted with Reptilase and challenged with ADP, epinephrine, collagen, or AA as inducers of platelet contractile activity. Inhibition by ticlopidine of ADP-induced clot retraction is shown in Fig. 4. Similar results were found employing 5-15 $\mu \mathrm{M}$ epinephrine, $0.2-1 \mu \mathrm{g} / \mathrm{ml}$ collagen, $0.2-0.6 \mathrm{mM} \mathrm{AA}$, or $1-3 \mathrm{U} / \mathrm{ml}$ thrombin (data not shown). When thrombin was the stimulus, Reptilase was omitted. It is also important to note that in control tubes, full retraction was achieved within 45-60 min, whereas no complete retraction was found in samples obtained following the administration of ticlopidine even after $6 \mathrm{~h}$ of incubation at $37^{\circ} \mathrm{C}$.

Inhibition of ${ }^{125}$ I-fibrinogen binding to platelets by ticlopidine. Exposure of platelet suspensions to ADP, epinephrine, collagen, thrombin, or AA induced an immediate time-dependent binding of ${ }^{125}$ I-fibrinogen which was complete within 3$5 \mathrm{~min}$ (the time period within which platelet aggregation is complete). Between 5 and $15 \mathrm{~min}$ after addition of labeled fibrinogen, $>85 \%$ of this could be displaced by a 20 -fold excess of unlabeled protein. Similar results were obtained when the labeled and unlabeled fibrinogen were added together at the initiation of the binding reaction. EDTA $(10 \mathrm{mM})$ inhibited $75-83 \%$ of the fibrinogen binding to stimulated platelets. Binding of fibrinogen was not affected at all when ticlopidine was added to platelets in vitro at concentrations as high as $100 \mu \mathrm{M}$. However, when administered in vivo, ticlopidine almost suppressed the interaction of fibrinogen with platelets exposed to ADP, epinephrine, collagen, AA, or thrombin (Fig. 5). The affinity of fibrinogen for platelets obtained before and after ticlopidine was studied quantitatively by incubating platelet 

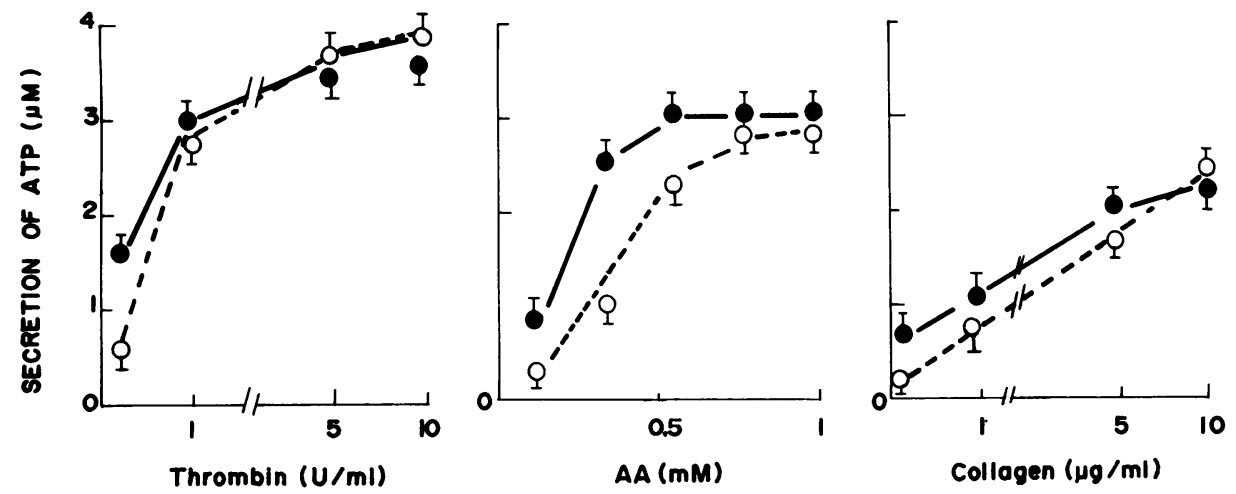

Figure 2. Effect of ticlopidine on the secretion of ATP from platelets. $50 \mu \mathrm{l}$ of firefly luciferase and luciferin (or of the buffer) were incubated with $0.5 \mathrm{ml}$ PRP that had been stirred at $37^{\circ} \mathrm{C}$ for $1 \mathrm{~min}$ at $1,000 \mathrm{rpm}$ in a lumi-aggregometer. After $30 \mathrm{~s}$, increasing concentrations of thrombin, AA, or collagen were added. ATP secretion was measured by comparing the luminescence produced by platelets $3 \mathrm{~min}$ after addition of each aggregating agent with that produced by known amounts of ATP added to unstimulated platelet suspensions. The sensitivity was such that $<0.1$

$\mu \mathrm{M}$ secreted ATP could be detected. Each circle is the mean \pm SEM of composite data from all eight subjects tested. Closed circles refer to preticlopidine and open circles to post-ticlopidine data. A statistically significant effect of ticlopidine $(P<0.01)$ on ATP secretion was only evident in response to thrombin $(0.2 \mathrm{U} / \mathrm{ml})$, AA $(0.2-0.4 \mathrm{mM})$, or collagen $(0.25 \mu \mathrm{g} / \mathrm{ml})$.

suspensions with $10 \mu \mathrm{M}$ ADP, $20 \mu \mathrm{M}$ epinephrine, $15 \mathrm{mU} /$ ml thrombin, $10 \mu \mathrm{M} \mathrm{AA}$, or $1 \mu \mathrm{g} / \mathrm{ml}$ collagen. After $3 \mathrm{~min}$, increasing concentrations (from 1.5 to $2,400 \mathrm{nM}$, final) of fibrinogen were added, and 5 min later free and platelet-bound fibrinogen were separated in silicone oil and counted. In suspensions of platelets obtained before ticlopidine administration, fibrinogen binding was concentration-related and reached a maximum at a final concentration of $\sim 200 \mathrm{nM}$. Ticlopidine did not affect this pattern, but reduced by $94-97 \%$ the binding in response to all agents tested (Table II). Scatchard analysis of the data (15) showed that ticlopidine did not affect the apparent affinity for fibrinogen of the "high affinity sites," whereas it significantly decreased the affinity of the platelet "low affinity sites." Therefore, the dissociation constant of the low affinity sites was 8-12-fold higher than normal ( $P$ $<0.01)$ in platelets obtained after the administration of the drug.

Results similar to those reported for the aggregation, the clot retraction, the secretion of ADP, the synthesis of $\mathrm{TxB}_{2}$, the binding of fibrinogen, and the measurement of cAMP of

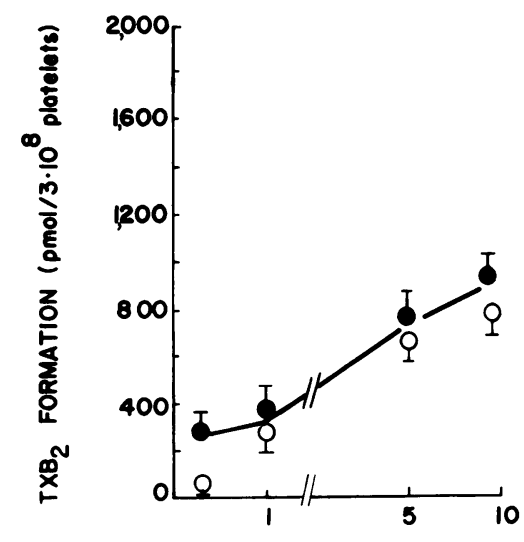

Thrombin (U/ml)

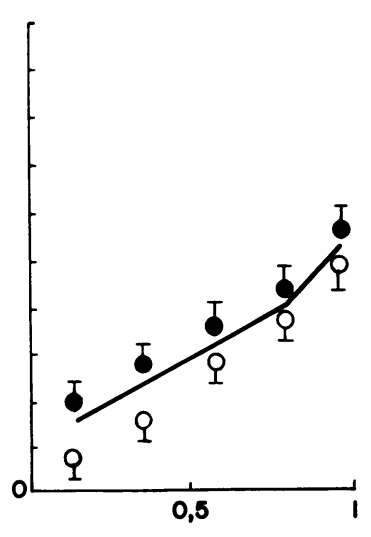

$A A(m M)$
Figure 3. Effect of ticlopidine on platelet $\mathrm{TxB}_{2}$ synthesis. $\mathrm{TxB}_{2}$ was measured in aliquots of the supernatant solution after completion of tests for platelet aggregation. Each circle is the mean \pm SEM of composite data from all eight volunteers studied. Closed circles refer to pre-ticlopidine and open circles to post-ticlopidine data. Significant platelets from subjects who had ingested ticlopidine were found in platelets from three patients who fulfilled all the criteria for the diagnosis of thrombasthenia (17-29).

Effect of ticlopidine on $P G E_{1}$ and $v W F$ binding to platelets. Drugs like carbenecillin and penicillin $G$ inhibit platelet function by impairing the interaction of several agonists with their specific receptors on the platelet surface membrane (48). We wondered, therefore, whether the inhibition of fibrinogen was a selective event or that ticlopidine might inhibit platelet function by interfering with the binding of other agonists to the platelet surface. We studied the binding to platelets of an inhibitor of platelet aggregation, $\mathrm{PGE}_{1}$, as well as that of the plasma protein vWF. PGE $_{1}$ was studied because recent reports $(49,50)$ showed that, at variance with aspirin (35), ticlopidine induces hypersensitivity of platelets to this prostaglandin. The binding of vWF was determined because this plasma protein is involved in the adhesion of platelets to the vascular subendothelium, a phenomenon thought to play a role in the arrest of bleeding $(29,36,44,45)$.

Following exposure to $\mathrm{PGE}_{1}$, resting platelets in PRP from

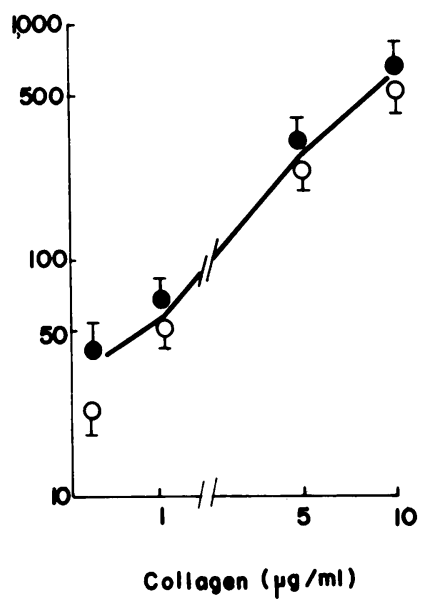

differences $(P<0.05)$ between the amounts of $\mathrm{TxB}_{2}$ produced before and after ticlopidine administration could only be found in response to thrombin $(0.2 \mathrm{U} / \mathrm{ml}), \mathrm{AA}(0.2$ and $0.4 \mathrm{mM})$, and collagen $(0.25$ $\mu \mathrm{g} / \mathrm{ml})$. 


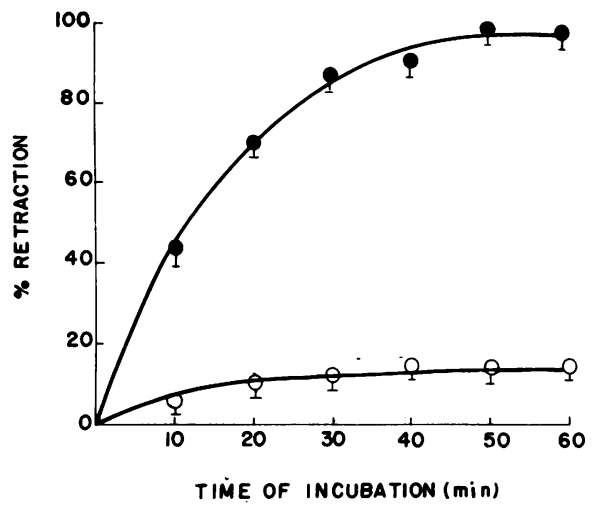

Figure 4. Effect of the administration of ticlopidine on the plateletfibrin clot retraction in response to $5 \mu \mathrm{M}$ ADP. A series of samples containing $0.5 \mathrm{ml}$ of unstirred PRP were incubated at $37^{\circ} \mathrm{C}$ with 5 $\mu \mathrm{M}$ (final) ADP. After $3 \mathrm{~min}, 0.1 \mathrm{ml}$ Reptilase was added and the mixture stirred with a small glass rod, then left inside the tube. At time intervals between 10 and $60 \mathrm{~min}$ after the addition of Reptilase the rod, to which the clot was attached, was gently removed by duplicate samples and the serum was measured in a microliter syringe. The amount of clot retraction was calculated by relating the volume of serum to the total amount of initial mixture and expressed as a percentage. Each circle is the mean \pm SEM of composite data from all eight subjects studied. Closed circles refer to pre-ticlopidine and open circles to post-ticlopidine data. Statistical analysis showed significant differences $(P$ always $<0.01)$ between the data obtained before and after the administration of this drug.

four untreated subjects bound this prostaglandin completely within 3-5 min. At $5 \mathrm{~min}$ and up to $30 \mathrm{~min},>75 \%$ of the labeled ligand could be displaced by a 100 -fold excess of unlabeled $\mathrm{PGE}_{1}$ but not by a similar molar excess of $\mathrm{PGF}_{2 \alpha}$ or $\mathrm{TxB}_{2}$. Ticlopidine either added in vitro at concentrations as high as $100 \mu \mathrm{M}$ or administered in vivo for $1 \mathrm{wk}$ at the dose of $250 \mathrm{mg}$ b.i.d. did not affect the patterns and the extent of this binding. This lack of effect was further confirmed in studies in which PRP obtained before and after the administration of ticlopidine was incubated with increasing concentration (from 16 to $512 \mathrm{nM}$, final) of $\mathrm{PGE}_{1}$ and free and plateletbound ligand determined 5 min later (Fig. 6).

When the binding of vWF to platelets was studied, it appeared that washed platelet suspensions exposed to ristocetin bound as much ${ }^{125} \mathrm{I}-\mathrm{vWF}$ after the administration of ticlopidine as before. However, further studies (Table II) showed that when exposed to thrombin, collagen, AA, or ADP, platelets obtained after the administration of ticlopidine bound 40-60\% less vWF than those from untreated subjects. Evidence is now accumulating $(15,31-34)$ to indicate that GPIIb-IIIa complex is the receptor for fibrinogen as well as for vWF on platelets exposed to naturally occurring aggregating agents. Therefore, we studied the effects of the administration of ticlopidine on this complex.

Effect of ticlopidine on the GPIIb-IIIa complex. To evaluate the potential effect of ticlopidine on GPIIb-IIIa complex we utilized monoclonal antibodies specific to this complex. Regardless of ticlopidine, binding of radiolabeled antibody B79.7 (or B59.2) to unstimulated platelets was complete in $1 \mathrm{~min}$. The amount of specific B79.7 binding at saturation was similar in platelets obtained before and after the administration of
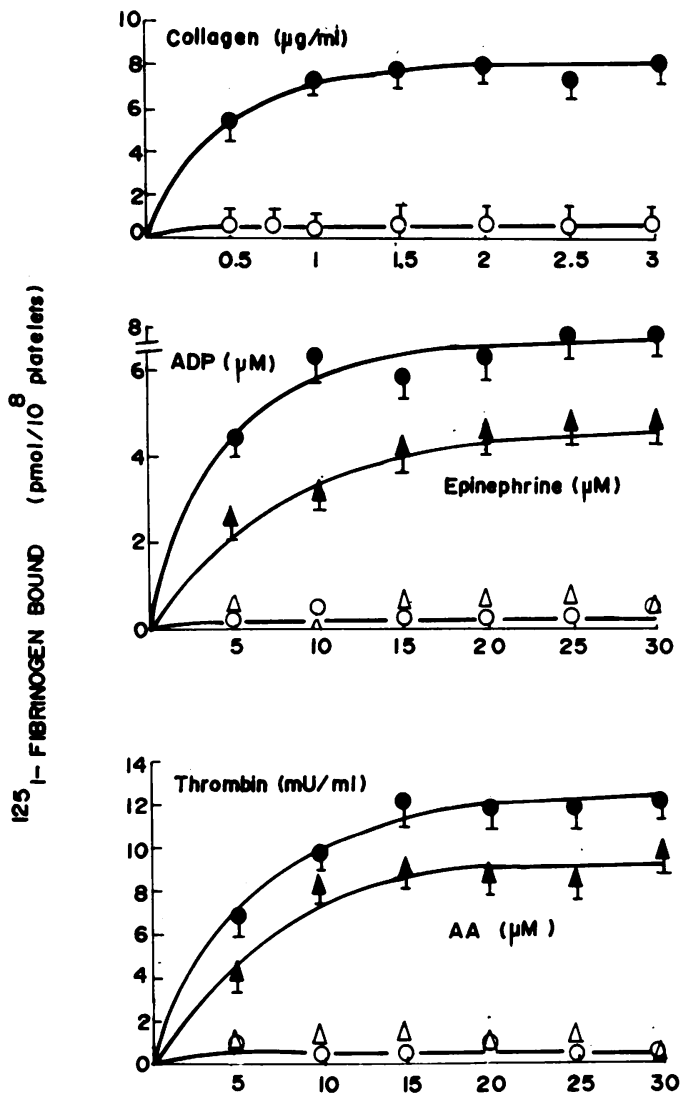

Figure 5. Effect of ticlopidine on the binding of fibrinogen to platelets. Aliquots of $0.5 \mathrm{ml}$ of unstirred suspensions of platelets $\left(5 \times 10^{8} /\right.$ $\mathrm{ml}$ ) from each volunteer were incubated at room temperature with 5-30 $\mu \mathrm{M}$ ADP (circles), epinephrine (triangles), or AA (triangles), $0.5-3 \mu \mathrm{g} / \mathrm{ml}$ collagen (circles) or $5-30 \mathrm{mU} / \mathrm{ml}$ thrombin (circles). After $3 \mathrm{~min}, 200 \mathrm{nM}$ (final concentration) of ${ }^{125}$ I-fibrinogen was added and $5 \mathrm{~min}$ later aliquots $(0.4 \mathrm{ml})$ of the mixture were layered onto $50 \mu \mathrm{l}$ of silicone oil in a $0.5 \mathrm{ml}$ micro-Eppendorf tube. Free and platelet-bound ${ }^{125}$ I-fibrinogen were separated by centrifugation for 2 min at $12,000 \mathrm{~g}$ at room temperature and counted separately. Specific fibrinogen binding was calculated by subtracting from the total bound the amount of binding in the presence of a 20 -fold excess of unlabeled protein. Specific fibrinogen binding was not corrected for the amount of this. protein bound. in the absence of stimulation. Closed symbols refer to pre-ticlopidine, open symbols to post-ticlopidine data. Note the almost complete suppression of the binding to platelets observed after the administration of ticlopidine ( $P$ always $<0.001$ ). The values reported are mean \pm SEM of composite data from all eight subjects studied.

ticlopidine $\left(3.62 \pm 1.16 \mathrm{pmol} / 10^{8}\right.$ platelets before vs. $3.47 \pm 2.16$ after ticlopidine, $P>0.1)$. Pretreatment of platelets with ADP $(30 \mu \mathrm{M})$, AA $(30 \mu \mathrm{M})$, or thrombin $(30 \mathrm{mU} / \mathrm{ml})$ did not affect the amount of binding observed in suspensions of platelets obtained before and after ticlopidine. Likewise, binding of antibody B59.2 to platelets was unaffected after 1 wk of administration of ticlopidine (not shown). In order to confirm that ticlopidine did not affect the GPIIb-IIIa complex quantitatively, we employed densitometric scannings of Periodic Acid-Schiff-stained gels of suspensions of platelets obtained before and after the administration of this drug. Fig. 7 shows a densitometric scan of one of these gels. It is representative 
Table II. Effect of the Administration of Ticlopidine on ${ }^{125}$ I-Fibrinogen and ${ }^{125}$ I-vWF Binding to Stimulated Platelets

\begin{tabular}{|c|c|c|c|c|}
\hline \multirow[b]{2}{*}{ Stimulus } & \multicolumn{2}{|c|}{ pmols ${ }^{125}$ I-fibrinogen-bound $/ 10^{8}$ platelets } & \multicolumn{2}{|c|}{$\mu \mathrm{g}{ }^{125} \mathrm{I}-\mathrm{vWF}$-bound $/ 10^{9}$ platelets } \\
\hline & Before & After & Before & After \\
\hline $\operatorname{ADP}(10 \mu \mathrm{M})$ & $6.73 \pm 0.46^{*}$ & $0.26 \pm 0.04 \ddagger$ & $3.76 \pm 0.54^{*}$ & $1.07 \pm 0.03 \ddagger$ \\
\hline Epinephrine $(20 \mu \mathrm{M})$ & $4.83 \pm 0.36^{*}$ & $0.18 \pm 0.06 \ddagger$ & $2.03 \pm 0.12^{*}$ & $0.16 \pm 0.06 \ddagger$ \\
\hline Collagen $(1 \mu \mathrm{g} / \mathrm{ml})$ & $7.68 \pm 0.15^{*}$ & $0.29 \pm 0.01 \ddagger$ & $6.42 \pm 0.39^{*}$ & $2.40 \pm 0.01 \ddagger$ \\
\hline $\mathrm{AA}(10 \mu \mathrm{M})$ & $8.57 \pm 0.51^{*}$ & $0.31 \pm 0.06 \ddagger$ & $7.52 \pm 0.61^{*}$ & $3.05 \pm 0.13 \ddagger$ \\
\hline Thrombin $(15 \mathrm{mU} / \mathrm{ml})$ & $12.63 \pm 1.13$ & $0.50 \pm 0.03 \ddagger$ & $15.07 \pm 1.83^{*}$ & $6.04 \pm 1.14 \ddagger$ \\
\hline Ionophore A23187 (15 $\mu \mathrm{M})$ & $9.36 \pm 0.73^{*}$ & $0.41 \pm 0.09 \ddagger$ & $10.04 \pm 0.97^{*}$ & $4.03 \pm 1.16 \ddagger$ \\
\hline Ristocetin $(1.5 \mathrm{mg} / \mathrm{ml})$ & ND & ND & $19.36 \pm 2.13$ & $20.16 \pm 1.96$ \\
\hline
\end{tabular}

Mean \pm SEM of composite data from eight subjects for fibrinogen and four for vWF. Platelet suspensions $\left(5 \times 10^{8} / \mathrm{ml}\right)$ were incubated with 10 $\mu \mathrm{M}$ ADP, $20 \mu \mathrm{M}$ epinephrine, $1 \mu \mathrm{g} / \mathrm{ml}$ collagen, $10 \mu \mathrm{M}$ AA, $15 \mathrm{mU} / \mathrm{ml}$ thrombin, $15 \mu \mathrm{M}$ ionophore A23187, or $1.5 \mathrm{mg} / \mathrm{ml}$ ristocetin. After 3 min, increasing concentrations of fibrinogen (from 1.5 to $2,400 \mathrm{nM}$, final) or of $\mathrm{vWF}$ (from 1.25 to $40 \mu \mathrm{g} / \mathrm{ml}$ ) were added and, at appropriate time intervals (i.e., $5 \mathrm{~min}$ for fibrinogen and $45 \mathrm{~min}$ for vWF binding), free and platelet-bound ligands were separated in silicone oil and counted. When ristocetin was used, formaldehyde-fixed platelets were employed. Both before and after ticlopidine administration, fibrinogen binding reached saturation at a final concentration of $\sim 200 \mathrm{nM}$, while vWF at a concentration of $\sim 20 \mu \mathrm{g} / \mathrm{ml}$. No difference $(P>0.05)$ was found between thrombin- and ristocetin-induced vWF binding to platelets. ${ }^{*} P<0.01$ thrombin- vs. ADP-, epinephrine-, collagen-, ionophore A23187-, or AA-induced binding (pre-ticlopidine). $¥ P<0.001$ before vs. after ticlopidine. ND, not detectable.

of the seven other platelet preparations tested. At variance with what was observed in gels of platelets from thrombasthenics (bottom of the figure), no apparent change in the region of glycoprotein IIb and IIIa was found in platelets obtained from ticlopidine-treated subjects.

Onset and cessation of the effect of ticlopidine on platelets. Following the cessation of ticlopidine, an immediate timedependent recovery of platelet aggregation and fibrinogen binding in response to $5 \mu \mathrm{M}$ ADP occurred which approached completion within 3-5 d (Fig. $8 \mathrm{~A}$ ). To further evaluate this observation, $250 \mathrm{mg}$ b.i.d. of ticlopidine was administered daily for 1 wk to four volunteers and the aggregation of PRP and the binding of fibrinogen in response to $5 \mu \mathrm{M}$ ADP was determined every $24 \mathrm{~h}$. As shown in Fig. $8 \mathrm{~B}$, the inhibitory effect of ticlopidine was very slow, and reached a maximum after a 3-5-d administration. These observations, together with

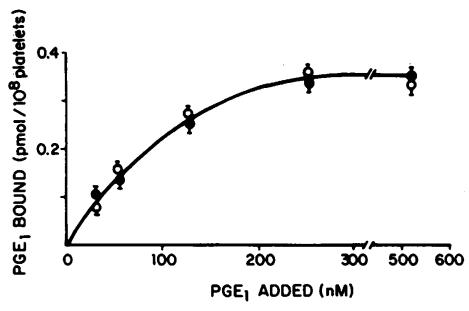

Figure 6. Effect of ticlopidine on the binding of prostaglandin $\mathrm{E}_{1}\left(\mathrm{PGE}_{1}\right)$ to platelets. Each point is the mean \pm SEM of composite data from four subjects. Aliquots of $0.5 \mathrm{ml}$ of unstirred PRP were incubated at $37^{\circ} \mathrm{C}$ with increasing amounts (from 16 to $512 \mathrm{nM}$, final) of $\mathrm{PGE}_{1}$ and, 5 min later, free and platelet-bound $\mathrm{PGE}_{1}$ were separated by centrifugation at $12,000 \mathrm{~g}$ for $2 \mathrm{~min}$. After centrifugation, the supernatant plasma and silicone oil were carefully aspirated with a Pasteur pipette and a cotton tip applicator was used to remove residual plasma from the walls of the tubes and the top of the platelet pellet. The tips of the tubes and appropriate amounts of the supernatant were placed in scintillation vials containing $1 \mathrm{ml}$ of Protosol and allowed to stand overnight to dissolve the pellet. A 10-ml vol of scintillation fluid was then added and the vials counted for radioactivity. Closed symbols refer to pre-ticlopidine, open symbols to post-ticlopidine data. the fact that ticlopidine is a potent inhibitor of platelet function only when administered in vivo, suggested that the platelet effect of ticlopidine could be mediated by a metabolite rather than the native drug. To further evaluate this possibility, washed platelets from untreated subjects were incubated either in control PFP or in the PFP of four subjects to whom 500 $\mathrm{mg}$ of ticlopidine had been administered for 1 wk. PFP of
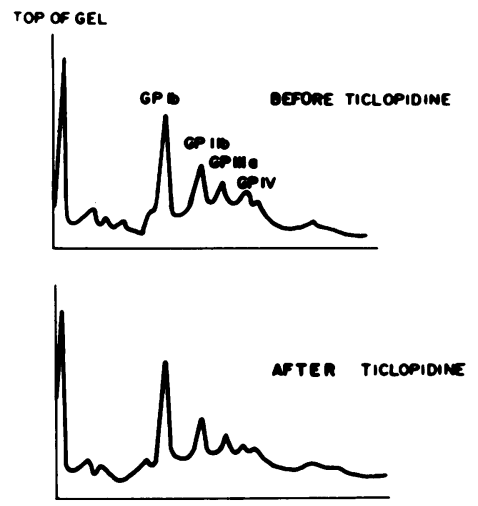

Figure 7. Typical scan records of Periodic AcidSchiff-stained SDS-polyacrylamide gels representing whole platelet glycoproteins from platelets obtained before and 1 wk after daily administration of ticlopidine. Reduced samples for whole platelet glycoprotein analysis were prepared by mixing $500 \mu \mathrm{l}$ of platelet suspension (containing $\sim 1-2 \times 10^{9}$ platelets) with an equal volume of $6 \%$ SDS solution and

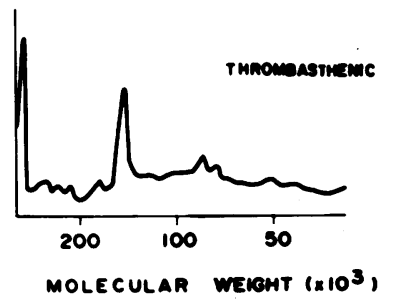

$250 \mu \mathrm{l}$ of a $0.2-\mathrm{M}$ solution of DTT. The samples were then heated at $100^{\circ} \mathrm{C}$ for 3 min, centrifuged at 12,000 $g$ for $10 \mathrm{~min}$, and loaded on polyacrylamide gels that were $1.5 \mathrm{~mm}$ thick and contained a bis-acrylamide ratio of $0.67 \%$ with a $7.5 \%$

(wt/vol) acrylamide. Gels were run at $40 \mathrm{~mA}$ constant current for 4$5 \mathrm{~h}$ in a vertical slab gel, fixed and stained with Schiff's reagent, and scanned in a spectrodensitometer connected with a density computer. The bottom part of the figure refers to the scan of a gel of whole platelet glycoproteins from one of the thrombasthenic patients studied. The lack of GPIIb-IIIa is evident in this record. 

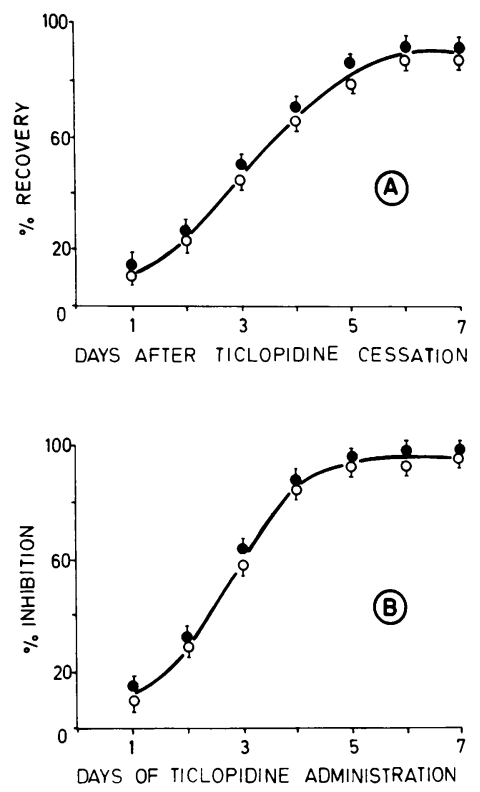

Figure 8. Onset and cessation of the effect of ticlopidine on platelets. $(A)$ After 1 wk of administration, ticlopidine was withdrawn and platelet aggregation (closed circles) in response to $5 \mu \mathrm{M}$ was determined for $7 \mathrm{~d}$ in parallel with the binding of ${ }^{125}$ I-fibrinogen (open circles). At least $5 \mathrm{~d}$ were required to achieve $90 \%$ of the aggregation and the binding found before starting the administration. The values reported are mean \pm SEM of composite data from all eight subjects studied. $(B)$ Four normal subjects (two males and two females aged 28-32 yr) who denied taking any medication donated blood. 9 vol of blood $(45 \mathrm{ml})$ were drawn into 1 vol $(5 \mathrm{ml}) 3.8 \%$ trisodium citrate. The subjects then ingested $500 \mathrm{mg}$ ticlopidine daily for $1 \mathrm{wk}$. Blood samples $(45 \mathrm{ml})$ were taken at daily intervals for $7 \mathrm{~d}$ and the aggregation of PRP (closed circles) in response to $5 \mu \mathrm{M}$ ADP and the binding of fibrinogen to washed platelets (open circles) determined. At least 4-5 d of ticlopidine administration were required to achieve $90 \%$ inhibition of the aggregation and of the binding of fibrinogen.

ticlopidine-treated subjects was obtained from blood collected 12-14 $\mathrm{h}$ after the last administration of this drug. When platelet aggregation, secretion, and $\mathrm{TxB}_{2}$ formation were determined after 90 min incubation in PFP, it appeared that plasma from subjects taking ticlopidine induced abnormalities of platelet function comparable to those described above for platelets from ticlopidine-treated subjects.

Effect of ticlopidine on the aggregation and binding of fibrinogen to rat platelets. Ticlopidine, as well as its isomer PCR 5325 (Fig. 9), is a weak lipophilic substance and can affect the fluidity of membrane lipids in rat platelets (Vallee, E., unpublished observations). Since platelet activation involves changes in membrane fluidity $(51,52)$, we wondered whether ticlopidine could induce abnormalities of platelet function by altering this membrane-associated process. To evaluate this, ticlopidine or its isomer were given by mouth to rats and, after $3 \mathrm{~d}$ of administration, platelet aggregation and fibrinogen binding were determined. Table III reports data from these studies. In spite of the fact that ticlopidine and PCR 5325 are able to induce comparable changes in the fluidity of platelet membrane lipids, only ticlopidine inhibited the aggregation and the binding of fibrinogen to platelets.

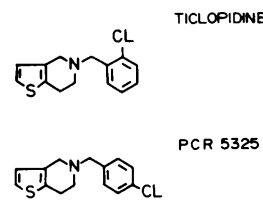

Figure 9. Structure of ticlopidine and its isomer PCR 5325. Pka of ticlopidine was 7.64.

\section{Discussion}

Previous reports have shown that ticlopidine significantly prolongs the skin bleeding time and inhibits the aggregation of platelets in response to a variety of agents (1). We have confirmed these observations, and relate them to a dramatic inhibition of fibrinogen and vWF binding to platelets in the absence of quantitative abnormalities of platelet membrane glycoproteins. Inhibition of platelet aggregation and clot retraction cannot be attributed to a direct effect of ticlopidine on fibrinogen, since similar inhibitory effects were found in PRP and in platelets washed free of fibrinogen. In addition, fibrinogen purified from four volunteers before and after $1 \mathrm{mo}$ of administration of ticlopidine ( $250 \mathrm{mg}$ b.i.d.) behaved identically in supporting the aggregation of washed platelets.

In agreement with our data, other groups have found a very slow onset and cessation of the effect of ticlopidine and an apparent discrepancy between the in vitro and ex vivo effects of this drug (1). This suggests that either ticlopidine acts through one or more active metabolites, or that 3-5 d are required to achieve plasma concentrations of the drug sufficient to cause the inhibitory effect observed. The latter possibility seems unlikely, since ticlopidine is completely cleared from the plasma within $6 \mathrm{~h}$ and no signs of accumulation have been found after repeated doses (53). Furthermore, abnormalities of platelet function comparable to those of ticlopidine-treated subjects can be observed when platelets from untreated subjects are incubated in PFP from subjects to whom ticlopidine has been administered.

We have found that, following the administration of ticlopidine, platelets exhibit impaired aggregation, clot retraction, and fibrinogen and vWF binding in response to a variety of agents. These in vitro abnormalities were associated with a prolonged skin bleeding time and are comparable to those found in patients with Glanzmann's thrombasthenia. Moreover, as in thrombasthenia $(1-3,17-21,54)$, platelets obtained after ticlopidine administration have normal shape change in response to ADP, thrombin, collagen, or AA, normal agglutination and binding of $\mathrm{vWF}$ in response to ristocetin, and decreased adhesion to glass surfaces.

It is known that prostacyclin either administered in vivo or added in vitro may inhibit the first wave of aggregation in response to $\operatorname{ADP}(35,55)$, the clot retraction (43), and the exposure of fibrinogen and vWF receptors on platelets (56, 57). However, at variance with ticlopidine, prostacyclin cannot be said to induce a thrombasthenic-like state in normal platelets, since these effects are associated with increases in intraplatelet cAMP able to inhibit platelet activation $(16,58)$.

The binding of fibrinogen or vWF to platelets involves activation of these cells $(24-29,31-34,44)$, and such activation is known to be triggered by a variety of cellular reactions. Among these, thromboxane synthesis, changes in intracellular cAMP, and translocations of calcium ions across the membranes are thought to be major events $(48,51,52)$. Our data make it unlikely that ticlopidine acts by affecting one or more of these basic events of platelet activation since, as in thrombasthenia, these processes are normal in platelets from ticlopidine-treated subjects. However, we observed that the hypersensitivity to $\mathrm{PGE}_{1}$ of ticlopidine-treated platelets from rats does not depend on abnormalities of the platelet receptor for this prostaglandin 


\begin{tabular}{|c|c|c|c|c|}
\hline \multirow[b]{2}{*}{ Inhibitor } & \multicolumn{2}{|l|}{ Aggregation } & \multicolumn{2}{|c|}{ Fibrinogen binding } \\
\hline & Before & After & Before & After \\
\hline \multicolumn{5}{|l|}{ Vehicle } \\
\hline Collagen $(1 \mu \mathrm{g} / \mathrm{ml})$ & $5.34 \pm 1.56$ & $5.16 \pm 1.32$ & $7.14 \pm 1.64$ & $7.57 \pm 0.65$ \\
\hline ADP $(10 \mu \mathrm{M})$ & $3.29 \pm 1.51$ & $4.12 \pm 1.60$ & $4.09 \pm 0.78$ & $4.64 \pm 0.16$ \\
\hline \multicolumn{5}{|l|}{ Ticlopidine } \\
\hline Collagen $(1 \mu \mathrm{g} / \mathrm{ml})$ & $4.91 \pm 1.19$ & $0.76 \pm 0.10 \ddagger \S$ & $7.52 \pm 0.46$ & $0.94 \pm 0.09 \ddagger \S$ \\
\hline ADP $(10 \mu \mathrm{M})$ & $3.21 \pm 0.13$ & $0.20 \pm 0.03 \ddagger \S$ & $4.26 \pm 1.12$ & $0.36 \pm 0.01 \neq \S$ \\
\hline \multicolumn{5}{|l|}{ PCR 5325} \\
\hline Collagen $(1 \mu \mathrm{g} / \mathrm{ml})$ & $4.86 \pm 1.31$ & $3.15 \pm 1.24$ & $6.97 \pm 0.86$ & $5.78 \pm 1.01$ \\
\hline $\operatorname{ADP}(10 \mu \mathrm{M})$ & $3.62 \pm 1.14$ & $2.97 \pm 0.66$ & $4.06 \pm 0.93$ & $3.24 \pm 0.77$ \\
\hline
\end{tabular}

15 CD-COBS rats (five times each group) weighing $200-250 \mathrm{~g}$ were given daily by mouth $200 \mathrm{mg} / \mathrm{kg}$ per body weight of ticlopidine or of its isomer PCR 5325 or of vehicle (distilled water). After $3 \mathrm{~d}$ of administration the animals were anesthetized by immersion in ether vapor and blood was collected by heart puncture. PRP was employed as such for aggregation studies or processed as described in methods for the preparation of platelet suspensions $\left(5-8 \times 10^{8}\right.$ platelets $\left./ \mathrm{ml}\right)$. Fibrinogen binding was determined as described above for human platelets. Platelet aggregation, studied as maximum light transmittance, was measured $3 \mathrm{~min}$ after the addition of an aggregating agent and expressed in units, $1 \mathrm{U}$ $=10 \%$ light transmittance. Fibrinogen binding is reported as picomoles of ligand bound $/ 10^{8}$ platelets. Binding of fibrinogen to rat platelets showed patterns quantitatively and qualitatively comparable to that of human platelets. * Each value is the mean of composite data from five animals. $\ddagger P<0.01$ before vs. after. $\S P<0.01$ vehicle vs. ticlopidine (both after). All other comparisons were not significant $(P>0.05$ ).

or on the stimulation of abnormally high levels of intraplatelet cAMP following this binding. Therefore, it is conceivable that other poorly understood mechanisms of platelet activation are affected by ticlopidine.

The nature of fibrinogen and vWF receptors exposed on the platelet surface following stimulation with naturally occurring aggregating agents is not precisely known, although most evidence suggests that they are, or are closely associated with GPIIb and IIIa. Platelets from thrombasthenic patients lack the GPIIb-IIIa complex $(22,23)$ and have absent binding of fibrinogen after stimulation with ADP (24-28) and impaired binding of vWF following exposure to thrombin (29); GPIIbIIla may form complexes with fibrinogen $(30)$ and monoclonal antibodies to GPIIb and/or IIIa inhibit the binding of fibrinogen and vWF to platelets $(15,31-34)$. Studies using ticlopidine indicate that this drug induces a dramatic inhibition of the binding of these adhesive proteins to the platelet surface without affecting the GPIIb-IIIa complex quantitatively. This suggests that either ticlopidine induces a qualitative defect in these glycoproteins or that molecular defects other than GPIIbIIIa deficiency may lead to a thrombasthenic state. The latter possibility is also suggested by the observations that: thrombasthenic platelets have abnormalities of surface proteins other than GPIIb and IIIa (59); more than one class of binding sites for fibrinogen and vWF have been described on the platelet surface $(14,15,25,28,34)$; and thrombasthenic platelets may bind fibrinogen and aggregate when exposed to chymotrypsin $(26,28)$.

Current evidence $(48,52,60)$ suggests that plasma membrane receptors are glycoproteins presumably embedded within the membrane's lipid bilayer. Since ticlopidine is a lipophilic substance and can alter the fluidity of platelet membranes in the rat, it might interfere with the binding of several agonists to the platelet surface, either by interacting directly with specific receptors or by affecting the surrounding lipid milieu. However, in spite of the fact that ticlopidine and its isomer PCR 5325 induce comparable changes in the fluidity of platelet membranes, our data show that only ticlopidine significantly inhibits the aggregation and the binding of fibrinogen to rat platelets (Table III). In addition, ticlopidine does not affect the binding of ADP to its high affinity receptor (61), or that of $\mathrm{PGE}_{1}$ to resting platelets (Fig. 6), and this drug impairs the binding of vWF only when platelets are exposed to some agents (Table II). Finally, the interaction of thromboxane or ADP with platelets is known to account only for $30-50 \%$ of the binding of fibrinogen or vWF observed in response to ADP or collagen $(12-15,44)$.

Taken together, these data suggest that the effect of ticlopidine on platelets is a novel and unique platelet phenomenon that, in addition to its obvious pharmacologic significance, could serve as an important probe for understanding the basic events leading to platelet activation.

\section{Acknowledgments}

The authors thank Drs. G. de Gaetano, M. B. Donati, M. Pannain, A. M. Capitanio, L. A. Monagle, A. Savino, E. Vallee, and L. M. Russo for helpful discussion, G. Truppa for expert technical assistance, and V. Piantadosi and P. Di Giuseppe for the illustrations.

\section{References}

1. de Gaetano, G., and V. Bertelè. 1983. Antiplatelet drugs and thrombosis prevention. Ticlopidine in perspective. Agents Actions. 14:109-112.

2. Caen, J. P., P. A. Castaldi, J. C. Leclerc, S. Inceman, M. J. Larrieu, M. Probst, and J. Bernard. 1966. Congenital bleeding disorders with long bleeding time and normal platelet count. I. Glanzmann's thrombasthenia (report of fifteen patients). Am. J. Med. 41:4-26. 
3. Zucker, M. B., J. H. Pert, and M. W. Hilgartner. 1966. Platelet function in a patient with thrombasthenia. Blood. 28:524-534.

4. Cross, M. J. 1964. Effect of fibrinogen on the aggregation of platelets by adenosine diphosphate-induced aggregation in human platelets. Thromb. Diath. Haemorrh. 12:524-527.

5. Brinkhaus, K. M., M. S. Read, and R. G. Mason. 1965. Plasma thrombocyte-agglutinating activity and fibrinogen synergism with adenosine diphosphate. Lab. Invest. 14:335-342.

6. Weiss, H. J., and J. Rogers. 1971. Fibrinogen and platelets in the primary arrest of bleeding. Studies in two patients with congenital afibrinogenemia. N. Engl. J. Med. 285:369-374.

7. Solum, N. O., and H. Stormorken. 1965. Influence of fibrinogen on the aggregation of washed human platelets induced by adenosine diphosphate, thrombin, collagen and adrenaline. Scand. J. Clin. Lab. Invest. 17(Suppl. 84):170-182.

8. Gugler, E., and E. F. Luscher. 1965. Platelet function in congenital afibrinogenemia. Thromb. Diath. Haemorrh. 14:361-373.

9. Inceman, S., J. Caen, and J. Bernard. 1966. Aggregation adhesion and viscous metamorphosis of platelets in congenital fibrinogen deficiencies. J. Lab. Clin. Med. 68:21-32.

10. Zucker, M. B., and L. Vroman. 1969. Platelet adhesion induced by fibrinogen adsorbed onto glass. Proc. Soc. Exp. Biol. Med. 131:318320.

11. Miller, J. L., A. J. Katz, and M. B. Feinstein. 1975. Plasmin inhibition of thrombin-induced platelet aggregation. Thromb. Diath. Haemorrh. 33:286-309.

12. Plow, E. F., and G. A. Marguerie. 1980. Induction of the fibrinogen receptor on human platelets by epinephrine and the combination of epinephrine and ADP. J. Biol. Chem. 255:10971-10977.

13. Bennett, J. G., G. Vilaire, and J. W. Burch. 1981. A role for prostaglandins and thromboxanes in the exposure of platelet fibrinogen receptors. J. Clin. Invest. 68:981-987.

14. Peerschke, E. 1982. Induction of human platelet fibrinogen receptors by epinephrine in the absence of released ADP. Blood. 60:71-76.

15. Di Minno, G., P. Thiagarajan, B. Perussia, J. Martinez, S. Shapiro, G. Trinchieri, and S. Murphy. 1983. Exposure of fibrinogen binding sites by collagen, arachidonic acid and ADP: inhibition by a monoclonal antibody to the glycoprotein IIb-IIIa complex. Blood. 61:140-148.

16. Graber, S. E., and J. Hawiger. 1982. Evidence that changes in platelet cyclic AMP levels regulate the fibrinogen receptor on platelets. J. Biol. Chem. 257:14606-14609.

17. Weiss, H. J., and S. Kochwa. 1968. Studies of platelet function and proteins in 3 patients with Glanzmann's thrombasthenia. J. Lab. Clin. Med. 71:153-165.

18. Cronberg, S. 1971. Abnormal behavior of platelets. In Platelet Aggregation. J. P. Caen, editor. Masson et Cie, Paris. 185-191.

19. Chediak, J., M. C. Telfer, B. Vander Laan, B. Maxey, and I. Cohen. 1979. Cycles of agglutination: disagglutination induced by ristocetin in thrombasthenic platelets. Br. J. Haematol. 43:113-126.

20. Caen, J. P., S. Cronberg, S. Levy-Toledano, P. Kubisz, and J. P. Pinkhas. 1971. New data on Glanzmann's thrombasthenia. Proc. Soc. Exp. Biol. Med. 136:1082-1086.

21. Malmsten, C., H. Kindhal, B. Samuelsson, S. Levy-Toledano, G. Toblem, and J. P. Caen. 1977. Thromboxane synthesis and the platelet release reaction in Bernard-Soulier syndrome, Thrombasthenia Glanzmann and Hermansky-Pudlak Syndrome. Br. J. Haematol. 35:511-520.

22. Nurden, A. T., and J. P. Caen. 1974. An abnormal platelet glycoprotein pattern in three cases of Glanzmann's thrombasthenia. Br. J. Haematol. 28:253-260.

23. Phillips, D. R., C. S. P. Jenkins, E. F. Luscher, and M. J. Larrieu. 1975. Molecular differences of exposed surface protein on thrombasthenic platelet plasma membranes. Nature (Lond.). 257:599_ 600 .
24. Bennett, J. S., and G. Vilaire. 1979. Exposure of platelet fibrinogen receptors by ADP and epinephrine. J. Clin. Invest. 64:13931401.

25. Peerschke, E. I., M. B. Zucker, R. A. Grant, J. J. Egan, and M. M. Johnson. 1980. Correlation between fibrinogen binding to human platelets and platelet aggregability. Blood. 55:841-847.

26. Mustard, J. F., R. L. Kinlough-Rathbone, M. A. Packham, D. W. Perry, E. J. Harfenist, and K. R. M. Pai. 1979. Comparison of fibrinogen association with normal and thrombasthenic platelets on exposure to ADP or chymotrypsin. Blood. 54:987-993.

27. Lee, H., A. T. Nurden, A. Thomaidis, and J. P. Caen. 1981. Relationship between fibrinogen binding and the platelet glycoprotein deficiencies in Glanzmann's thrombasthenia type I and II. $B r$. $J$. Haematol. 48:47-57.

28. Kornecki, E., S. Niewiarowski, T. A. Morinelli, and $M$. Kloczewiak. 1981. Effect of chymotrypsin and adenosine diphosphate on the exposure of fibrinogen receptors on normal human and Glanzmann's thrombasthenic platelets. J. Biol. Chem. 256:5696-5701.

29. Ruggieri, Z. M., R. Bader, and L. De Marco. 1982. Glanzmann thrombasthenia: deficient binding of von Willebrand Factor to thrombinstimulated platelets. Proc. Natl. Acad. Sci. USA. 79:6038-6041.

30. Nachman, R. L., and L. L. K. Leung. 1982. Complex formation of platelet membrane glycoproteins IIb and IIla with fibrinogen. $J$. Clin. Invest. 69:263-269.

31. Coller, B. S., E. I. Peerschke, L. E. Scudder, and C. A. Sullivan. 1983. A murine monoclonal antibody that completely blocks the binding of fibrinogen to platelets produces a thrombasthenic-like state in normal platelets and binds to glycoprotein IIb and/or IIIa. J. Clin. Invest. 72:325-338.

32. McEver, R. P., E. M. Bennett, and M. M. Martin. 1983. Identification of two structurally and functionally distinct sites on human platelet membrane glycoprotein IIb-IIIa using monoclonal antibodies. J. Biol. Chem. 258:5269-5275.

33. Bennett, J. S., J. A. Hoxie, S. F. Leitman, G. Vilaire, and D. B. Cines. 1983. Inhibition of fibrinogen binding to stimulated human platelets by a monoclonal antibody. Proc. Natl. Acad. Sci. USA. 80:2417-2421.

34. Ruggieri, Z. M., L. De Marco, L. Gatti, R. Bader, and R. R. Montgomery. 1983. Platelets have more than one binding site for von Willebrand Factor. J. Clin. Invest. 72:1-12.

35. Di Minno, G., M. J. Silver, and G. de Gaetano. 1979. Prostaglandins as inhibitors of human platelet aggregation. $\mathrm{Br}$. J. Haematol. 43:637-647.

36. Di Minno, G., V. Bertelè, L. Bianchi, B. Barbieri, C. Cerletti, E. Dejana, G. de Gaetano, and M. J. Silver. 1981. Effects of an epoxymethano stable analogue of prostaglandin endoperoxides (U46619) on human platelets. Thromb. Haemostasis. 48:103-105.

37. McFarlane, A. S. 1958. Efficient trace labelling of proteins with iodine. Nature (Lond.). 182:53.

38. Hawiger, J., S. Niewiarowski, V. Gurewick, and D. P. Thomas. 1970. Measurement of fibrinogen and fibrin degradation products in serum by staphylococcal clumping test. J. Lab. Clin. Med. 75:93-108.

39. Martinez, J., R. R. Holburn, S. S. Shapiro, and A. J. Erslev. 1974. Fibrinogen Philadelphia. A hereditary hypodysfibrinogenemia characterized by fibrinogen hypercatabolism. J. Clin. Invest. 53:600611.

40. Weber, K., and M. Osborn. 1969. The reliability of molecular weight determinations by sodium dodecyl sulfate-polyacrylamide gel electrophoresis. J. Biol. Chem. 244:4406-4412.

41. Di Minno, G., M. J. Silver, and S. Murphy. 1983. Monitoring the entry of new platelets into the circulation after ingestion of aspirin. Blood. 61:1081-1085.

42. Remuzzi, G., A. Benigni, P. Dodesini, A. Schieppati, M. Livio, G. de Gaetano, J. S. Day, W. L. Smith, E. Pinca, P. Patrignani, and C. Patrono. 1983. Reduced platelet thromboxane formation in uremia. 
Evidence for a functional cyclo-oxygenase defect. J. Clin. Invest. 71:762-768.

43. Di Minno, G., V. Bertele, C. Cerletti, G. de Gaetano, and M. J. Silver. 1982. Arachidonic acid induces human platelet fibrin retraction. The role of platelet cyclic endoperoxides. Thromb. Res. 25:299-306.

44. Di Minno, G., S. S. Shapiro, P. M. Catalano, L. De Marco, and S. Murphy. 1983. The role of ADP secretion and thromboxane synthesis in Factor VIII binding to platelets. Blood. 62:186-190.

45. Kao, K. J., S. V. Pizzo, and P. A. McKee. 1979. Demonstration and characterization of specific binding sites for Factor VIII/von Willebrand Factor on human platelets. J. Clin. Invest. 63:656-664.

46. Clementson, K. J., A. Capitanio, and E. F. Luscher. 1979. High resolution two-dimensional gel electrophoresis of the proteins and glycoproteins of human blood platelets and platelet membranes. Biochim. Biophys. Acta. 553:11-16.

47. McDonald, J. W. D., and R. K. Stuart. 1974. Interaction of prostaglandin E1 and E2 in regulation of cyclic AMP and aggregation in human platelets: evidence for a common prostaglandin receptor. $J$. Lab. Clin. Med. 84:111-121.

48. Shattil, S. J., J. S. Bennett, M. McDonough, and J. Turnbull. 1980. Carbenecillin and penicillin $G$ inhibit platelet function in vitro by impairing the interaction of agonists with the platelet surface. $J$. Clin. Invest. 65:329-337.

49. Ashida, S. I., and Y. Abiko. 1979. Mode of action of ticlopidine in inhibition of platelet aggregation in the rat. Thromb. Haemostasis. 41:436-449.

50. Regnault, F. 1981. Hypothetic mechanism of ticlopidineinduced hypersensitivity to PGE1 in rat platelets. Thromb. Res. 21:157-164.

51. Nathan, I., G. Fleisher, A. Dvilansky, A. Levine, and A. H. Parola. 1980. Membrane dynamic alterations associated with activation of human platelets by thrombin. Biochim. Biophys. Acta. 598:417421.
52. Shattil, S. J., and J. S. Bennett. 1981. Platelets and their membranes in hemostasis: physiology and pathophysiology. Ann. Intern. Med. 94:108-118.

53. Knudsen, J. B., and J. Gormsen. 1979. The effect of ticlopidine on platelet function in normal volunteers and in patients with platelet hyperaggregability in vitro. Thromb. Res. 16:663-671.

54. Cohen, I., T. Glaser, and U. Seligsohn. 1975. Effects of ADP and ATP on bovine fibrinogen and ristocetin-induced platelet aggregation in Glanzmann's thrombasthenia. Br. J. Haematol. 31:343-347.

55. Machin, S. J., D. A. F. Chamone, G. Defreyn, and J. Vermylen. 1981. The effect of clinical prostacyclin infusions in advanced arterial disease on platelet function and plasma 6-keto PGF levels. $\mathrm{Br}$. J. Haematol. 47:413-422.

56. Hawiger, J., S. Parkinson, and S. Timmons. 1980. Prostacyclin inhibits mobilization of fibrinogen-binding sites on human ADP and thrombin treated platelets. Nature (Lond.). 283:195-197.

57. Fujimoto, T., S. Ohara, and J. Hawiger. 1982. Thrombininduced exposure and prostacyclin inhibition of the receptor for Factor VIII/von Willebrand Factor on human platelets. J. Clin. Invest. 69:1212-1222.

58. Majerus, P. W. 1983. Arachidonate metabolism in vascular disorders. J. Clin. Invest. 72:1521-1525.

59. McGregor, J. L., K. J. Clemetson, E. James, A. Capitanio, M. Decharanne, and E. F. Luscher. 1981. Glycoproteins of platelet membranes from Glanzmann's thrombasthenia. A comparison with normal using carbohydrate-specific or protein-specific labelling techniques and high resolution two-dimensional gel electrophoresis. Eur. J. Biochem. 116:379-388.

60. Lefkowitz, R. J., and T. Michel. 1983. Plasma membrane receptors. J. Clin. Invest. 72:1185-1189.

61. Lips, U. P. M., J. J. Sixma, and M. E. Schiphorst. 1980. The effect of ticlopidine administration to humans on the binding of adenosine diphosphate to blood platelets. Thromb. Res. 17:19-27. 